\title{
Laringoscopio híbrido: Una opción de costo razonable para el abordaje de la vía aérea difícil. Reporte de un caso
}

\author{
Hybrid laryngoscope: A reasonable option cost for approaching the airway \\ difficulty. A case report
}

\author{
Christiam Mauricio Maya Marcillo1,a, Jesús Alberto Meléndez Ordoñez ${ }^{1, a,{ }^{*}}$, Ana Ruth Montes Ríos ${ }^{1, b}$ \\ Hospital Juárez de México. \\ Médico residente de Anestesiología. \\ Médico adjunto al Servicio de Anestesiología.
}

Fecha de recepción: 13 de diciembre de 2020 / Fecha de aceptación: 30 de enero de 2021

\begin{abstract}
The laryngoscope is a primary tool that every medical professional who performs in airway care should know how to use. Although it's an irreplaceable tool, in the last decade have been considered transformations and modifications in them that have allowed the medical professional, especially the anesthesiologist to perform successfully for critical management especially in the context of unanticipated difficult airway, because most of the time the only available resource at hand is the laryngoscope and a malleable stylet that guides the orotracheal. The new technological age of visual instruments such as video cameras and photographs many of these with small sizes, has been used in the manufacture of video laryngoscopes that today are used, which have managed to approach the aerea in a minimally traumatic way and also safeguard lives. Our hydrid video laryngoscope is a handcrafted tool made of high-quality elements, strength, durability and low cost.
\end{abstract}

Key words: Video laryngoscope, difficult airway, intubation, clinical case, treatment.

\section{RESUMEN}

El laringoscopio es una herramienta primordial que todo profesional médico que se desempeña en la atención de la vía aérea debería saber utilizar. Pese a ser un dispositivo insustituible, en la última década se han considerado transformaciones y modificaciones en los mismos que le han permitido al profesional de la medicina, fundamentalmente al anestesiólogo, desempeñarse exitosamente durante el manejo crítico especialmente en el contexto de vía aérea difícil no anticipada, en el que la mayoría de las veces el único recurso disponible a la mano es el laringoscopio y un estilete maleable que sirve de guía para dirigir la sonda orotraqueal. La nueva era tecnológica de los instrumentos visuales como cámaras de video y fotografía, (muchos de estos con tamaños reducidos) han sido empleados en la fabricación de videolaringoscopios que hoy en día se utilizan y que han logrado abordar la vía aérea de manera mínimamente traumática, así mismo, salvaguardar vidas. Nuestro videolaringoscopio híbrido es una herramienta artesanal fabricada con elementos de alta calidad, resistencia, durabilidad y bajo costo.

Palabras clave: Videolaringoscopio, vía aérea difícil, intubación, caso clínico, tratamiento.

\section{Introducción}

a intubación endotraqueal es el estándar de oro para asegurar la vía aérea de un paciente que requiere manejo quirúrgico electivo o de urgencia, y una de las destrezas más importantes que realizan todos los médicos que se desempeñan en las diferentes especialidades médico quirúrgicas[1].
Si se trata de un paciente con trauma de columna cervical, o que por el contrario no pueda ser movilizado libremente por las características de su enfermedad que ponen en riesgo sistemas vitales como el tallo cerebral, médula espinal y/o cerebro, la videolaringoscopia es una técnica de intubación endotraqueal indirecta muy utilizada; la cual no solo ha facilitado el trabajo del especialista en vía aérea, sino también un fiel indicador de dismi- 
nución de mortalidad en pacientes con vía aérea difícil anticipada y no anticipada obteniendo resultados favorables para el paciente como: disminución del trauma de cavidad orofaríngea, menor respuesta hemodinámica derivada de la maniobra y acceso guiado bajo visión video asistida de las estructuras periglóticas[1],[2].

Aunque hay quienes defienden la laringoscopia directa rutinaria para el entrenamiento de los residentes, hay quienes afirman en diversos estudios que la visión laríngea mejora en comparación con el uso de laringoscopia directa en varios escenarios de la práctica profesional, y particularmente los novatos han demostrado mejores tasas de éxito con laringoscopia por video en comparación con laringoscopia convencional de rutina en aproximadamente el $90 \%$ de los intentos, más en aquellos casos que corresponden a vías aéreas difíciles confirmadas[3],[4],[5].

La videolaringoscopia tiene la ventaja no solo de poder usarse en adultos, sino también en el contexto de vía aérea difícill del paciente pediátrico, logrando la intubación endotraqueal en gran parte de los pacientes que incluso no solo demuestran predictores de vía aérea difícil, si no en vía aérea difícil corroborada bajo visión laringoscópica directa. ${ }^{4,5}$

Aún no hay estudios suficientes que demuestren que los laringoscopios artesanales sean útiles en escenarios de vía aérea difícil, pero en México ya se han realizado estudios pilotos y pioneros que demuestran que se puede desarrollar un videolaringoscopio con excelente visión de las estructuras perigloticas incluyendo las cuerdas vocales, con excelentes tasas de éxito en intubación por video asistencia y sobretodo, costo razonable al alcance de cualquier médico que se desempeñe en el manejo de la vía aérea trabajando en ella de manera adecuada[6].

\section{Material y Métodos}

Modelo desarrollado con la utilización de impresoras 3D, basado en una combinación de diferentes tipos de videolaringoscopios en el mercado; se obtuvo el modelo físico de una hoja curva número 3, construido en material plástico Acrílonitrilo Butadieno Estireno (ABS).

Este dispositivo cuenta con un mango convencional y una hoja curva. La hoja incorpora en la parte inferior una cámara boroscópica de LEDs, con una dimensión de $7 \mathrm{~mm}$ de diámetro compatible con varios sistemas operativos (Android ${ }^{\circledR}$, Microsoft ${ }^{\circledR}$ ) mediante el software gratuito de código abierto (Ycamera), para ser utilizados en tabletas digitales, ordenadores portátiles o smartphones, brindando la capacidad de obtener imágenes digitales y videos en una resolución de $640 * 480$ pixeles. Con estas características, es posible guardar imágenes y videos, transmitir en tiempo real a un monitor tipo televisión smart TV como un segundo monitor, con lo cual podemos obtener una visión indirecta de las estructuras anatómicas. Además, brinda la posibilidad de visualizar las estructuras de forma directa gracias a los LEDs incorporados a la cámara.

\section{Caso clínico}

Mujer de 36 años de edad con antecedente de obesidad grado 1, hipertensa crónica en manejo con enalapril e hidroclorotiazida. Con el diagnóstico de miomatosis uterina; quien es programada de forma electiva para realizar histerectomía total abdominal (por características propias del mioma considerado mioma gigante con invasión del lecho vascular uterino) con técnica anestésica general (Figura 1). A la exploración física con regulares condiciones generales, edema de miembros inferiores grado 1 y cuello corto, ancho, móvil sin adenomegalias, tiroides asciende con la deglución, predictores de la vía aérea Mallampati clase III, Patil Aldreti clase III $(5,9 \mathrm{~cm})$, distancia esternomentoniana clase IV $(10,9 \mathrm{~cm})$, apertura bucal máxima $4,5 \mathrm{~cm}$, protusión mandibular clase II, tórax con murmullo pulmonar conservado en ambas bases pulmonares, abdomen se observa tumoración redondeada en hipogastrio y área pélvica. Signos vitales 150/90 mm/Hg, frecuencia cardíaca 80 latidos por minuto, frecuencia respiratoria 18 respiraciones por minuto, temperatura axilar $36,0^{\circ} \mathrm{C}$, saturación basal $94 \%$. Peso $68 \mathrm{~kg}$, talla $154 \mathrm{~cm}$, índice de masa corporal $28 \mathrm{k} / \mathrm{m}^{2}$.

\section{Intervenciones terapéuticas}

Previo a verificación de la máquina de anestesia, preparación de medicamentos anestésicos y verificación del funcionamiento del videolaringoscopio híbrido (Figura 2), se trasladó paciente

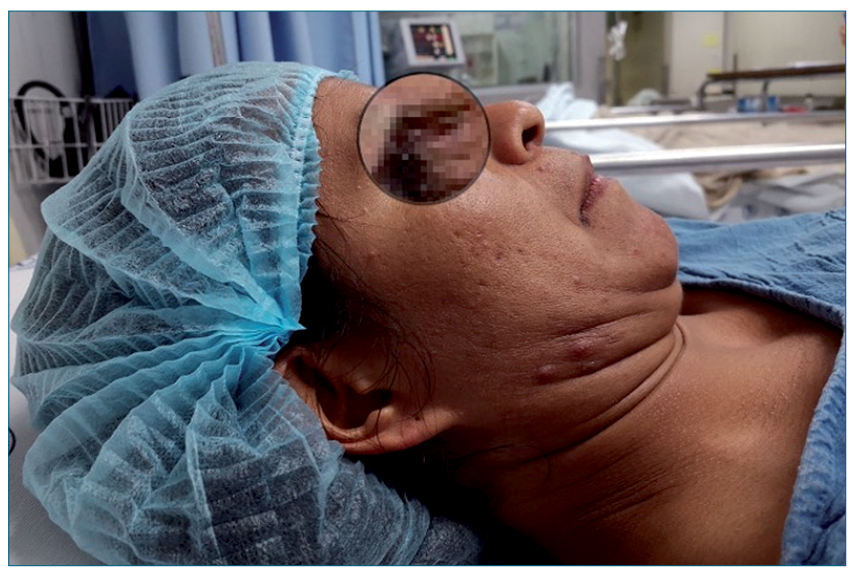

Figura 1.

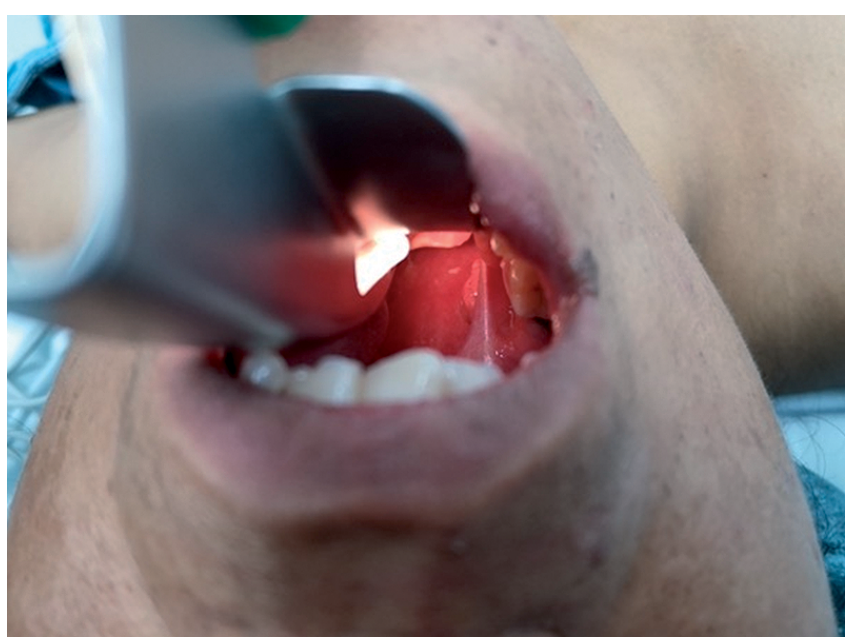

Figura 2. 
a unidad de cirugía ginecológica, realizamos preoxigenación con máscara facial y 2 capacidades vitales, posteriormente iniciamos inducción anestésica con fentanil $300 \mu \mathrm{g}$ endovenosos, rocuronio $40 \mathrm{mg}$ endovenoso, propofol $120 \mathrm{mg}$ endovenosos. Posterior a latencia farmacológica se procedió a efectuar laringoscopia convencional con hoja curva número 3, observando Cormark-Lehane 3 (Figura 3). Posteriormente, efectuamos laringoscopía indirecta con videolaringoscopio híbrido visualizando estructuras periglóticas de manera completa (Figura 4), obteniendo imágenes nítidas y finalmente canulando tráquea con tubo endotraqueal Murphy número 7.5; acoplando a circuito anestésico, auscultando campos pulmonares simétricos, obteniendo curva de capnografía, se verifica estabilidad hemodinámica y constantes vitales para poder iniciar procedimiento quirúrgico sin inconvenientes.

\section{Discusión}

Nuestro videolaringoscopio híbrido es un dispositivo que se realizó con creatividad y sobre todo con el interés de mejorar la visualización de las estructuras periglóticas que permita lograr el abordaje de la vía aérea de forma segura, rápida con menor trauma y mejor respuesta hemodinámica derivada de la maniobra.

Una vía aérea difícil se define como la situación clínica en la que un anestesiólogo con capacitación convencional experimenta dificultad con la ventilación con máscara facial de la vía aérea superior, dificultad intubación traqueal, o ambas[6],[7]. La videolaringoscopia sin duda alguna ha mejorado el éxito durante la intubación orotraqueal, ya sea en el ámbito rutinario o en aquella vía aérea dificíl no anticipada. Los videolaringoscopios son instrumentos costosos, por ende, de díficil acceso para el personal médico. Teniendo en cuenta esta definición, los videoscopios "artesanales" son instrumentos alternativos que permiten el abordaje de la vía aérea con relativa facilidad[8].

En el año 2016, Velázquez-Murillo, describe de una manera muy sencilla el uso de este tipo de dispositivo artesanal en pacientes con vía aérea difícil como lo son las quemaduras de cuello, abscesos periamigdalinos, tumores de laringe, esófago y cuello, con visión mejorada de las estructuras góticas enfatizando el costo razonable del instrumento[6].

Nuestro videolaringoscopio incluye la ventaja de ejecutar la intubación orotraqueal ya sea en modalidad directa (sin uso de videocámara) o indirecta (con asistencia de la videocámara) realizadas de forma simultánea, lo que puede ser benéfico en el ámbito de la enseñanza.

\section{Conclusión}

La videolaringoscopia artesanal es un instrumento que permite una visualización indirecta clara y detallada de las estructuras periglóticas, permitiendo el abordaje de la vía aérea. Tomando en cuenta el costo razonable de los artículos que se requieren para su construcción, es una opción valiosa al alcance de los médicos que se desempeñan en el manejo de la vía aérea.

Finalmente, nuestra intención es evidenciar la utilidad que presenta el instrumento cuando el médico con imaginación se

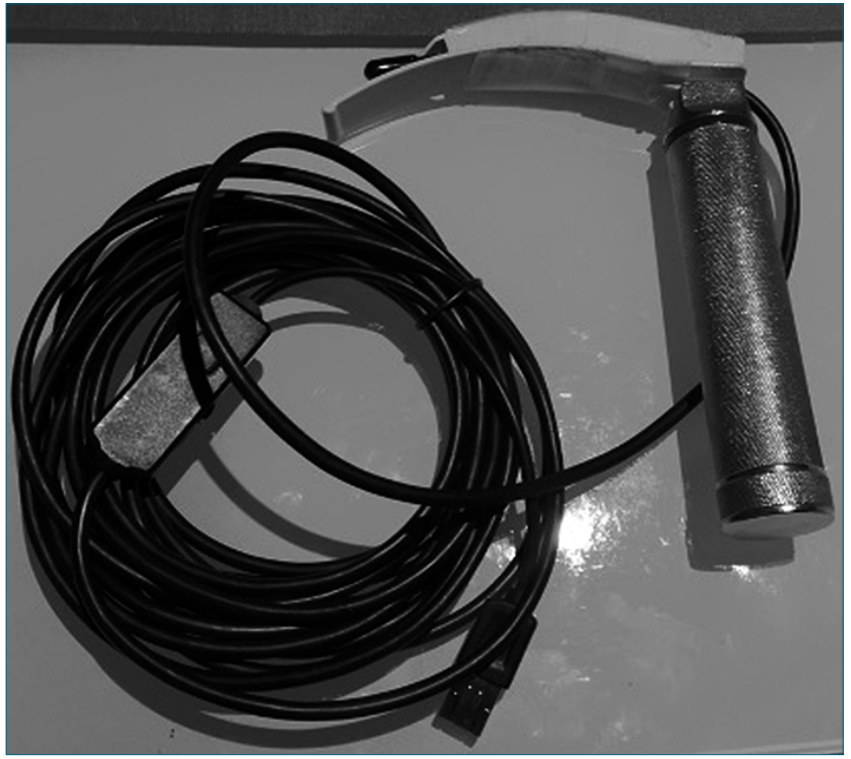

Figura 3.

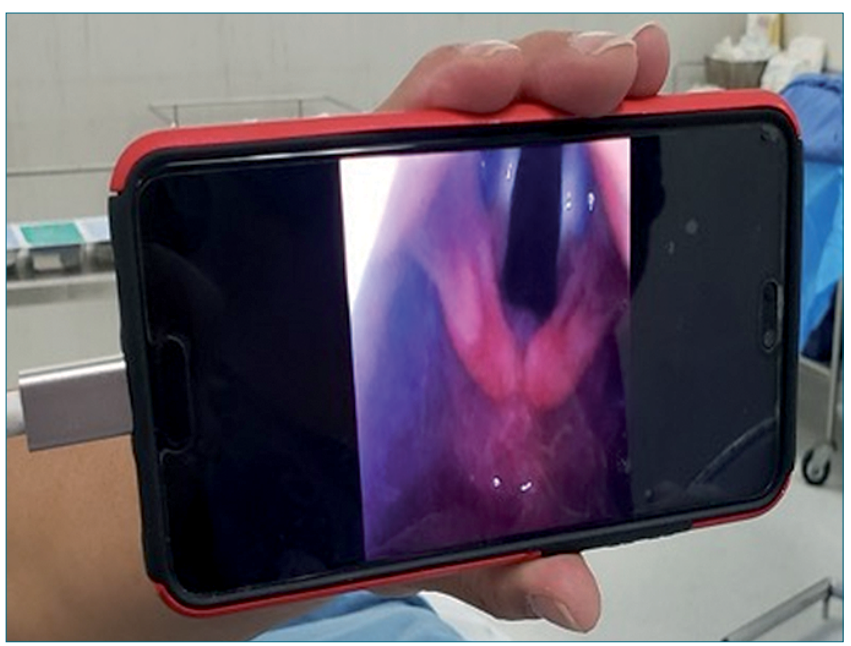

Figura 4.

enfrenta a una vía aérea difícil, recalcando que esta es una alternativa con costo accesible y no de primera opción, además es de vital importancia y en todo momento contar con el material, equipo e insumos necesarios para el abordaje de una vía aérea difícil.

\section{Referencias}

1. Capek AL. Comparación de Macintosh y McGrath (R) en un centro terciario de cabeza y cuello. RIVER ST, HOBOKEN 070305774. Nueva Jersey. 2013;68(8):111.

2. Abdelgadir IS, Phillips RS, Singh D, Moncreiff MP, Lumsden JL. Videolaringoscopia versus laringoscopia directa para la intubación traqueal en niños (excluidos los recién nacidos). Cochrane Database Syst Rev. 2017;5:CD011413. PMID:28539007

3. Aziz MF, Dillman D, Fu R, Brambrink AM. Eficacia compara- 
tiva del videolaringoscopio C-MAC frente a la laringoscopia directa en el contexto de la vía aérea difícil prevista. Surv Anesthesiol. 2013;57(1):46-7. https://doi.org/10.1097/01. SA.0000425541.04628.30.

4. Grunwell K, Pp M, M. K, A. W, K. S, D., et al. Tendencia y resultados del uso de videolaringoscopio en las UCIP. Medicina de cuidados intensivos pediátricos: una revista de la Sociedad de Medicina de Cuidados Intensivos y la Federación Mundial de Sociedades de Cuidados Intensivos y Críticos de Pediatría. 2017; 18 (8): 741

5. Silverberg MJ, Li N, Acquah SO, Kory PD. Comparación de la videolaringoscopia versus la laringoscopia directa durante la intubación endotraqueal urgente: un ensayo controlado aleatorio. Medicina de cuidados intensivos. 2015;43(3):636-641.
6. Velázquez-Murillo G. Videolaringoscopio Artesanal Macintosh. Anestesia en México. 2016;28(1):40-5.

7. Apfelbaum JL, Hagberg CA, Caplan RA, Blitt CD, Connis RT, Nickinovich DG, et al.; American Society of Anesthesiologists Task Force on Management of the Difficult Airway. Practice guidelines for management of the difficult airway: an updated report by the American Society of Anesthesiologists Task Force on Management of the Difficult Airway. Anesthesiology. 2013 Feb;118(2):251-70. https://doi.org/10.1097/ ALN.0b013e31827773b2 PMID:23364566

8. Osorio-Cervantes LJ, Jesús Gamboa-López G, Bautista-Martínez J. Eficacia del video laringoscopio (VividTrac TM) en vía aérea difícil. Evidencia Médica e Investigación en Salud. 2014;7 S1:24-5. 